\title{
Corporativismo y relaciones laborales en España: una historia de la organización del trabajo como sistema de Política Social
}

\author{
Sergio FERNANDEZ RIQUELME \\ Universidad de Murcia \\ serferi@um.es
}

Recibido: 2-11-09

Aceptado: $28-5-10$

\section{RESUMEN}

Este trabajo realiza una aproximación histórica al desarrollo instrumental de los "expedientes técnicos" de naturaleza tecnocrática en España, y en especial de carácter corporativo. Para ello establecemos cinco fases generales en su itinerario histórico, buscando las claves generales y compartidas en la definición técnica de los sistemas de gestión ejecutiva y de representación legislativa, resaltando el impacto de las teorías centradas en la idea del "trabajo organizado". Para ello introducimos las claves filosóficas, tanto políticas como jurídicas, de un fenómeno, no siempre advertido, de relación entre economía y política, en clave de gestión técnica y armonía social; una tendencia presente en el complejo proceso de modernización española, y que en el caso del corporativismo, ha generado y genera una Política social condicionada por criterios sociolaborales.

Palabras clave: Acción colectiva, Corporativismo, Relaciones laborales

\section{Corporatism and industrial relations in Spain: a history of work organization as a system of Social Policy}

\begin{abstract}
This article realizes a historical approximation to the instrumental development of the Corporatism as a modality of Social Policy in Spain, and especially in relation to the industrial relations system. For it we establish five general phases in the technical definition the systems of executive management and of legislative representation, highlighting the impact of the theories centred on the idea of the "organized work". For it, we introduce the philosophical keys, so much juridical as policies, of a phenomenon, not always warned, of relation between technology and policy; present phenomenon in the western societies, and that in case of the corporatism, it has generated and generates a social Policy determined by sociolabour criteria.
\end{abstract}

Keywords: Collective action, Corporatism, Industrial relations.

\section{REFERENCIA NORMALIZADA}

Fernández Riquelme, S. (2011). Corporativismo y relaciones laborales en España: una historia de la organización del trabajo como sistema de Política Social. Cuadernos de Relaciones Laborales Vol. 29, Núm. 1, p. 157175.

SUMARIO: 1. Introducción, 2. Itinerario histórico del Corporativismo sociolaboral en España, 3. Conclusiones. Referencias bibliográficas. 


\section{Introducción}

El impacto de la economía en las sociedades europeas en el siglo XIX alteró las formas vitales de la tradicional Gemeinschaft (comunidad), dando lugar a una nueva Gemeinschaft (sociedad) definida por la división funcional del trabajo (Durkheim, 1982: 5). Pero este impacto de "lo económico" en la configuración social (mental y material) llegó, como era lógico, a los límites de lo "político", especialmente al situarse el problema obrero o "Cuestión social" como la consecuencia más visible de esta transformación (Freund, 1998: 279). Así comenzó a configurarse el Estado social europeo, tras el fracaso de las primeras experiencias de "democracia social", obra, entre otros, de Louis Blanc [1811-1882] o Henri de Saint-Simon [1760-1825]. La Política social de naturaleza estatal nos remite, pues, a la Sozialpolitik germana, germen de la primera legislación sociolaboral impulsada por el gobierno Bismarck (Fortshoff, 1967: 23-24). Esta escuela fue concretando, en gran parte del viejo Continente, la concepción de la Política social como mediación jurídica entre las exigencias de lo político (bien-común) y lo económico (bien-estar), y donde las relaciones laborales se situaban, en última instancia, como instrumento para la realización de sus fines (Molina, 2004: 38). Ahora bien, en la conceptuación de dichas relaciones encontró un lugar destacado la primera doctrina corporativista, fruto del idealismo alemán, del guildismo inglés, del catolicismo social, del gremialismo italiano o del funcionalismo sociológico francés.

"Una de las más ambiciosas aproximaciones a los problemas de la política social -sostiene J. Molina- es aquella que identifica el desarrollo de esta última con la elaboración de una teoría del Estado o de la Sociedad corporativistas" (Molina, 2004: 143). Así nos encontramos con una doctrina que defendía la organización de la colectividad sobre la base de asociaciones representantes de los intereses y de las actividades profesionales. Proponía, en líneas generales, y sobre el ideal de solidaridad orgánica de los intereses concretos y de las fórmulas de colaboración que de ellos se pueden derivar, la remoción o la neutralización de los elementos conflictivos propios de la nueva sociedad industrial: la competencia en el plano económico, la lucha de clases en el plano social, y la diferenciación ideológica en el plano político (Fernández Riquelme, 2008).

Por ello, y frente a la polisemia terminológica a la que es sometido el concepto corporativo (identidad profesional, intervencionismo de Estado, proteccionismo económico, grupos de presión. etc.), en estas páginas lo abordamos como una doctrina político-social que propugnaba la "organización política y económica de la vida social", sobre la base del pluralismo de asociaciones representativas de los intereses y actividades profesionales (bien los modernos sindicatos, bien los viejos gremios), y en virtud de los nuevos principios políticos de función, representación y organización. Podemos hablar, pues, del corporativismo como doctrina social fundada, históricamente, en la mediación entre trabajo (obreros) y capital (patronos), protagonistas de la Cuestión social, con una finalidad declarada: la armonía social (Incisa, 1982: 431432). 
Sobre la relación entre Política social y Corporativismo, Patrick de Laubier señalaba como toda Política social "dependía y depende de una voluntad política y de una situación económica"; de ellas surgen sus creaciones, se determina su posibilidad y también surgen sus contradicciones. La solidaridad social, institución mediadora por excelencia del corporativismo, resultaba del grado de intervención social de la forma política estatal y el grado de respuesta de la forma socioeconómica profesional. Voluntariamente aceptada o coactivamente impuesta, esta solidaridad fue determinada, en última instancia por un Estado que legitimaba la Política social; mientras, los sindicatos y colectivos profesionales aspiraban a influir decisivamente en el desarrollo de la Política social a la manera corporativa (profesional), como elemento mediador entre el gobierno (elemento político) y la patronal (elemento económico). Así la Política social corporativa estaba "destinada a hacer desaparecer obligatoriamente los antagonismos de clases y las divergencias entre las categorías productivas", pero su parcial vinculación con los regímenes autoritarios de la era de entreguerras [1919-1939] situaron sus propuestas en la marginalidad política tras el fin de la II Guerra mundial. Pero la tarea mediadora del corporativismo como Política social, "l'intermédiairie des organisations corporatives" (De Laubier, 1984: 41-43), resurgió como instrumento de análisis heurístico, bajo las aún polémicas formas neocorporativas, en los grandes pactos sociales, económicos y laborales de la Europa de los años sesenta del siglo XX.

En España, el proceso de construcción de la Política social fue similar al experimentado en Europa, aunque más lento ante una industrialización tardía y ante especificidades culturales (persistencia del magisterio católico y sus formas de asistencia caritativa, influencia de la filosofía social krausista) e institucionales (debilidad del Estado nacional). Situación que explica las numerosas propuestas corporativistas en el seno del primer reformismo español, de notable impronta krausista, que asumirá progresivamente ciertos principios corporativos en el ámbito sociolaboral (representación paritaria, Tribunales de arbitraje, Senado corporativo), sólo realizados integralmente bajo gobiernos autoritarios, y en clara interrelación con el fenómeno sindical, como alternativa o complemento. Así, el itinerario del Corporativismo español, ligado a la representación de intereses (Linz, 1988: 68-6), renovado ante los retos presentes de la organización sociolaboral española (De Alos, 2008: 123-124), y enraizado en un conflicto social que aparece como constante propia de las sociedades complejas (Edwards, 1992: 139) es, pues, objeto del presente trabajo.

\section{Itinerario histórico del Corporativismo sociolaboral en España.}

El Real Decreto de 6 de diciembre de 1836 suprimió definitivamente cualquier vestigio de la vieja organización gremial en España, recogiendo la proclama realizada al respecto en las Cortes de Cádiz (1808). Triunfaba el liberalismo anticorporativo español, cuarenta años después de la promulgación de la Ley Le Chapelier francesa. El decreto español garantizaba la total libertad de empresa y trabajo, deslindando los 
campos patronal y obrero, aunque sin reconocer ningún derecho formal a la asociación por motivos laborales. Pero muchos de los viejos gremios subsistieron en forma de coaliciones patronales y sociedades profesionales, mientras la Real Orden de 1853 prohibía toda asociación sindical. Lo mismo ocurrió con las doctrinas fundadas en el organicismo social, restringidas al minoritario socialismo mutualista, a ciertas especulaciones krausistas y a un tradicionalismo hispano asociado al "carlismo en armas" (Primera Guerra Carlista, 1833-1840).

Este escenario anticorporativo se mantuvo incólume durante gran parte del siglo XIX, al igual que las restricciones a la organización sindical (sólo comenzada a superar con la Ley de Asociaciones de 1887); pero a finales de la centuria encontramos cierta recuperación doctrinal ligada una nueva situación nacional: el impacto tardío de la economía industrial y a la crisis de legitimidad del sistema político vigente. Comenzaba la historia del moderno corporativismo español, vinculado al proceso de constitución de la moderna forma política estatal y nacional en España (García Canales, 1977: 67-69) y, especialmente, al impacto de la Cuestión Social en nuestro país, y dónde el fenómeno de la "negociación colectiva" comenzaría a jugar un papel básico, no sin problemas ideológicos e institucionales (Sánchez Reinón, 1996: 21).

En España, la recuperación doctrinal del organicismo social a mediados del siglo XIX será obra del krausismo y del catolicismo social. Ambas escuelas coincidirán en la sistematización de la primera Política social nacional, que integró, si bien parcialmente, el papel de la Corporación en los mecanismos de relaciones laborales de la incipiente reforma social. El Corporativismo, concebido por los primeros reformadores sociales españoles como medio de superación de la "lucha de clases", empezó a ser valorado como ingrediente del incipiente sistema español de relaciones laborales. Gumersindo de Azcárate [1840-1917] desde el krauso-institucionismo, Joaquín Costa [1846-1911] desde el regeneracionismo, o Severino Aznar [1870-1959] desde el catolicismo social, fueron algunos de los pioneros en la valoración de la corporación como sistema de representación político-social del trabajo organizado (patronal y obrero), bajo el principio de "armonía social". Pero estas viejas aspiraciones interclasistas, compartidas por liberales y socialistas de formación organicista ("teoría orgánica de la sociedad"), sólo comenzó a ser realidad políticosocial de la mano de la "reforma social autoritaria" implantada por la Dictadura de Primo de Rivera, fue limitado por los Jurados mixtos republicanos, se convirtió en elemento de control social por parte del Estado franquista, y finalmente apareció desarrollado de manera no siempre advertida en los mecanismos extraparlamentarios de la naciente democracia española.

A) Los Tribunales de Arbitraje durante la Restauración [1876-1923].

El inicio de la historia del corporativismo moderno en España se puede datar con los pioneros estudios gremiales de E. Pérez Pujol, L. Tramoyeres, J. Uña o J. Otero Valentín. Con sus obras se abría una primera etapa durante los años Restauración [1876-1923], que culminaba la reconstrucción del ideal organicista realizada por el krausismo y el tradicionalismo católico, y anunciaba el florecimiento doctrinal y organizativo del corporativismo desde la crisis de 1917. Pese a la gran crisis de 1898, 
que mostró la debilidad de los símbolos e instituciones del Estado-Nación español, el corporativismo no tradujo su florecimiento doctrinal en una paralela institucionalización política y social. Entre 1877 y 1917 el corporativismo se limitó a las esferas de la Reforma social española, que culminaría con los Tribunales de arbitraje establecidos en el cinturón industrial de Barcelona. Las reformas electorales de 1890 y de 1907 no recogieron las propuestas krausistas y tradicionalistas en pro de la introducción del sufragio orgánico ni la representación corporativa. Aunque en 1907 se introdujo la composición paritaria en el seno de el Instituto de Reformas sociales (IRS), sólo la crisis social y económica, escenificada en la Huelga general revolucionaria de 1917, fomentó la creación de tribunales de arbitraje sociolaboral, y difundió distintas propuestas de un Parlamento o Senado corporativo, como hizo el mismo filósofo liberal José Ortega y Gasset en 1918, o el frustrado proyecto de "democracia industrial" del un sector del sindicalismo socialista español (Barrio Alonso, 1996: 34-37)

El sistema demoliberal de la Restauración permitió un cierto pluralismo políticosocial, pese al monopolio gubernamental de los partidos dinásticos oficiales. En el esquema político planteado por Antonio Cánovas del Castillo [1828-1897] este pluralismo se limitaba aún a las redes caciquiles, a nivel territorial, y relaciones clientelares, a nivel personal, continuando con cierta herencia anticorporativa y antigremial del liberalismo histórico isabelino. Pese al nuevo pluralismo sociolaboral, agrupado en organizaciones mutualistas y profesionales, y asociado al notable desarrollo económico del periodo (García Delgado, 2002: 15), el único instrumento legal permisivo era el artículo 13 de la Constitución de 1876, que permitía un asociacionismo obrero o profesional sometido a la potestad gubernamental, aunque vacío de desarrollo legislativo e institucional (en especial ante el nacimiento de la AIT).

Una propuesta del Marqués de Cáceres, de 6 de diciembre de 1876, pretendía dotar a la realidad asociativa de un marco legislativo que permitiera su libre desenvolvimiento y de unos organismos mediadores, reconocidos como Jurados mixtos. Esta petición no tuvo éxito, pero marcó el camino para la Ley de Asociaciones de 1887 (iniciada por un proyecto de 1881). La discusión parlamentaria del dicha Ley mostró las diversas sensibilidades de la elite política del Régimen ante la Cuestión social y ante el fenómeno obrero. Al respecto, el liberal krausista Segismundo Moret [1838-1913] defendió la libre asociación obrera frente a las críticas de Vadillo a la "amenaza internacionalista". La promulgación de esta Ley de asociaciones permitió, con todo, la génesis de diversas organizaciones colegiales y obreras (PSOE, UGT y Círculos católicos); aunque la posterior Ley de 2 de septiembre de 1896, concedió al gobierno de turno la facultad de suprimir o cerrar asociaciones contrarias al "orden público" (Valera, Juan, 2001: 25)

Así, tras el primer proyecto de ley sobre Jurados mixtos durante la I República (1873), en 1883 Segismundo Moret refrendó un decreto por el que se encomendaba a la Comisión de Reformas Sociales la confección de un proyecto de Jurados, y en abril de 1884 se formuló un cuestionario al respecto. En 1891 la Comisión elaboró su ponencia, proponiendo la creación de los Jurados Industriales; éstos estarían 
compuestos por un presidente y un número de vocales comprendido entre ocho y treinta, repartidos paritariamente entre trabajadores y empresarios. El pleno de los Jurados de dividía en tres secciones: delegación tutelar (organismo inspector), mesa de conciliación y sala jurisdiccional (conocimiento y resolución de las cuestiones presentadas por vía contenciosa. Sobre el documento oficial, varios vocales de la CRS presentaron dictámenes al respeto: en 1891 Daniel Balaciart formuló un proyecto de Jurados Mixtos de Consulta y Arbitraje (compuestos por un presidente y seis vocales, tres patronos y tres obreros, con competencias de "laudo judicial") y Miguel de Castells sobre Jurados Mixtos Arbitrales, donde los vocales tenían la capacidad de dictar la sentencia; en 1901, Pedro Moreno Rodríguez planteó la constitución de Tribunales Industriales, compuestos por un Juez de primera instancia y seis jurados (tres patronos designados por el litigante obrero y tres obreros designados por el litigante patrono).

Ninguno de estos dictámenes llegaron a buen puerto, pero todo comenzaría a cambiar con llegada al trono español de Alfonso XIII [1902-1931], y la aparición de una nueva generación de políticos y estadistas, imbuidos en el horizonte del regeneracionismo y del reformismo; era el inicio de lo que Molina denomina como "monarquía de la reforma social" (Molina, 2004), aunque todavía en las coordenadas del programa social de Cánovas. En este contexto, el Ministro de la Gobernación Antonio García Alix [1852-1911] recogió los dictámenes de la CRS y presentó el 27 de Octubre de 1903 un proyecto de Ley a las Cortes sobre los Jurados mixtos; este infructuoso proyecto fue recogido por el nuevo ministro de la Gobernación, el Conde de Romanones [1863-1950], que lo presentó al Senado 17 de febrero de 1906, donde quedó paralizado. Pese a estos reveses, en 1907 se alcanzó la primera realización directamente corporativa, aunque, eso sí, parcial; se introdujo la representación corporativa en el seno del organigrama del Instituto de Reformas social (vocales estatales, sindicales y patronales). Finalmente, en 1908 se aprobaron las primeras leyes estatales sobre organización paritaria del mundo del trabajo: Ley de Conciliación y arbitraje y Ley de tribunales industriales (completadas con la Ley de Huelgas de 1909).

Nacía una legislación corporativa aún limitada, cuyo objetivo primordial residía en frenar los conflictos sociolaborales y el creciente número de huelgas (De Rey, 1992; 45); así la concebía Gabriel Maura [1879-1963]. Esta primera corporativización de la relaciones industriales presentaba una doble finalidad: la primera, derivada del organicismo social "compartido", pretendía la reducción de los conflictos derivados del trabajo asalariado a través de mecanismos y organismos jurídicos "paritarios"; la segunda, surgida de la necesidades gubernamentales de pacificación social y aumento de la productividad, buscaba la integración institucional de un movimiento obrero, visto como radicalizado, en organismos de colaboración interclasistas (Montero Aroca, 1976: 35), limitando en gran medida la posibilidad de "control obrero" de la gestión empresarial.

La aprobación final del proyecto de Juan de la Cierva y Peñafiel [1862-1938] sobre organización de Tribunales de Arbitraje, dio lugar a la Ley de Tribunales Industriales de 19 de mayo de 1908. Este texto establecía la creación de Tribunales 
industriales en las cabezas de partido judicial donde el Gobierno estimara oportuno a petición de obreros y patronos. Se encontrarían presididos por un Juez de Primera Instancia, y por tres jurados elegidos por el litigante obrero y otros tres por el litigante patrono (seleccionados de una lista de jurados elegidos por sufragio cada dos años). Su procedimiento, sencillo y breve, culminaba con un juicio verbal, a cuyo término el tribunal dictada sentencia, acordada en votación. Aquí encontramos el espíritu y la labor "armonizadora" del Instituto de Reformas sociales (1903), y del Instituto Nacional de Previsión (1908). Ambas entidades fueron el escenario dónde $\mathrm{M}^{\mathrm{a}}$ Dolores de la Calle sitúa el punto de convergencia las primeras corrientes de raíz socioorganicista en España; corrientes conscientes de la necesidad de reforma del Estado liberal "individualista" desde la creación en 1883 de la Comisión de Reforma Sociales (CRS). En ellas tuvieron un papel destacado krausistas de renombre como Urbano González [1848-1904] y Gumersindo de Azcárate [1840-1917], tecnócratas como José Marvá [1846-1942], o reformistas católico-sociales como José Maluquer y Salvador [1863-1931], José Gascón y Marín [1875-1962], el jurista Eduardo Sanz y Escartín [1855-1939] o el sociólogo Severino Aznar (De la Calle, 1989: 46).

Pero la Ley de 1908 tuvo que ser reformada en 1912, estableciendo el recurso de casación ante las sentencias del tribunal, la reducción del número de jurados de seis a cuatro y se les otorgaban dietas (para garantizar su celebración ante posibles bajas) o dar facultad al juez-presidente para entender del asunto y resolverlo cuando en segunda citación no se reunía número suficiente de vocales. Este modelo estuvo vigente entre 1912 y 1926 con escasa implantación y menor rendimiento. Así lo denunció Severino Aznar, subrayando la parquedad de la intervención corporativa del Estado; para Aznar, la verdadera Reforma social solo partiría de la reconstrucción de las organizaciones "intermedias" de autoayuda (gremial, municipal y familiar), laminadas en el siglo pasado por el liberalismo doctrinario. Tras el estudio de las cuestiones sobre el bienestar de los trabajadores, llegaba la hora de buscar "soluciones armonizadoras entre capital y trabajo".

En este proceso reformista, el presidente del Gobierno José Canalejas presentó el 6 de mayo de 1911 un proyecto de Ley sobre las asociaciones obreras de gran trascendencia. Partiendo de la necesidad de intervencionismo estatal en el control asociativo, definió la asociación profesional como aquellas "que tengan por objeto el estudio, fomento y defensa de los intereses económicos, intelectuales y morales de industrias, profesiones u oficios", subrayando la obligación de su registro en las Delegaciones de Estadística del IRS. Establecía la facultad de éstas en la designación de las representaciones de carácter social y desarrollar actividades de asistencia social interna (Cooperativas, Socorros mutuos), aunque siempre respetando la libertad individual de los miembros (Del Rey, 1992: 24). Se diseñaron marcos sectoriales y locales de diálogo salarial, jurisdicciones específicas de mediación industrial, dando espacios de representación y participación a los sindicatos obreros, se podría neutralizar el recurso prerrevolucionario por la huela y la "acción directa", y desterrar la práctica empresarial al "lock out". José Luis Monereo recordaba que la filosofía subyacente a dichos proyectos respondía, junto con la lógica organicista, a la nueva 
concepción de la empresa como "organización productiva"; ésta la definía como institución "objetiva" de "colaboración comunitarista" (Monereo: 333).

Esta legislación generaba un nuevo escenario "pactista", dónde la UGT negociaba directamente con la Federación Patronal Madrileña. En Barcelona, la grave situación de conflictividad social y de agitación sindical y política conllevó la mayor extensión e intensidad de estas prácticas. A las mismas se unieron distintas propuestas de mayor calado político, ante las noticias del Parlamento profesional proyectado por el primer ministro David Lloyd George [1863-1945] en 1919 para Gran Bretaña (IRS, 1919), o la previsión de la Constitución de Weimar sobre un "Consejo Económico" (Vicente Santamaría de Paredes [1853-1924] y su obra El Concepto de sociedad (1901). 165) de funciones consultivas y de iniciativa parlamentaria (mero organismo asesor que integraba ciertos grupos de intereses, eminentemente sindicales, sin cuestionamiento alguno del sufragio universal). Así el IRS preveía "Consejos de cooperación industrial" en su proyecto de Ley de contrato de trabajo (Real orden de 3 de enero de 1921) como posibilidad de intermediación entre las reivindicaciones obreras y las necesidades directivas (Estudios económicos y sociales, 1922). León Martín Granizo recordaba los diversos proyectos sobre Consejos paritarios industriales entre 1919 y 1924 surgidos de la Institución, los debates entre las distintas sensibilidades sobre las cuotas de participación internas, sobre los medios de control obrero o sobre el alcance de la futura legislación social.

El mismo presidente de Fomento, el catalán Pedro Gual Villalbí [1885-1968], comenzó a defender Comités paritarios sectoriales, Comisiones mixtas interclasistas, Tribunales de arbitraje provinciales, colegios y corporaciones profesionales locales y regionales; incluso hablaba ya de lo inevitable de un Parlamento de representación corporativa. Asimismo, las principales Cámaras provinciales debatían sobre un futuro "Parlamento del Trabajo" (Zancada, 1929: 143). Se trataba de integrar, localmente, al obrerismo reformista, descentralizar el sistema jurídico socio-laboral, estabilizar el orden socioeconómico, e invadir campos reivindicados en exclusiva por el sindicalismo revolucionario; todo ello para alcanzar la estabilidad productiva de la economía a corto y largo plazo, y en especial, eliminando la perenne sombra perturbadora de un movimiento obrero mitificado como capaz de subvertir el orden establecido. Junto al desastre militar, la desestabilización política y la recesión económica, la Huelga revolucionaria de agosto de 1917 marcó el principio del fin para las aspiraciones corporativas del liberalismo reformista y del socialismo moderado en la arena de la Restauración (que la ola de huelgas de 1918 que hizo tambalearse al gobierno Romanones y la gran huelga de 1919 en La Canadiense de Barcelona confirmaron).

Pero la idea de un nuevo Parlamento industrial para España, a imitación de la propuesta por Lloyd George, fue desechada bajo los sucesivos gobiernos de Maura, Sánchez de Toca, Allendesalazar. Como señala Ángeles Barrio estos años del "trienio bolchevique" asistieron a un espectacular incremento de la violencia sociolaboral en las calles e industrias españolas, especialmente barcelonesas, que se tradujo en el fenómeno paramilitar del pistolerismo entre organizaciones patronales, que llamaban a la intervención de la autoridad militar, y del sindicalismo revolucionario, tendente a 
la utilización de la acción directa (Elorza, Arranz y Del Rey, 1986: 5). Fernando de los Ríos se sumaba a la transformación revolucionaria del socialismo, abandonando su Cátedra académica, y Juan Díaz del Moral [1870-1848] elogiaba las numerosas ocupaciones de tierras en Andalucía. Así, la composición corporativa de las Juntas locales mostraron escasa eficacia ante la persistencia de las redes clientelares de funcionamiento político; funcionaron irregularmente contados Tribunales corporativos de arbitraje; la representación de vocales sindicales y patronales en los organismos del IRS fue normalizada hasta los estertores de la Restauración, y las promulgadas Ley de Huelgas y Ley Tribunales de arbitraje y de Consejos de conciliación no resultaron de la eficacia con la que habían sido concebidas. Esta fue la realidad del primer corporativismo institucional, la propia realidad de la Política social de la Restauración.

Tras esta situación crítica planteada por el "trienio bolchevique", el 9 de julio de 1919 Antonio Maura presentó un proyecto sobre la constitución de Sindicatos obreros que pretendía generalizar la acción mediadora entre organismos colectivos que ejercían la misma profesión y poseedores de intereses comunes. A partir de la libre y lógica sindicación de obreros y patronos, era necesario un órgano de representación conjunta para la negociación y firma de los contratos colectivos de trabajo, un "ente corporativo integro" que conciliase los intereses comunes, un "sindicato profesional" constituido a partir de reuniones de obreros censados para constituir el sindicato, elegir representantes facultativos, y negociar con la Patronal o la Administración pública. Por ello se conectaban la Ley de Consejos de conciliación y arbitraje industrial de 19 de mayo de 1908 que establece el arbitraje voluntario, y Real Decreto del 24 de mayo de 1919 que establece los primeros comités paritarios en la industria (que desarrollaba uno anterior de 15 de marzo donde junto a la regulación de la jornada de 8 horas se impulsaba su creación). A estas medidas se unió primer régimen legal constitutivo de las corporaciones agrarias en España, establecido de manera general por el D. de 30 de abril de 1919, obra del entonces Ministro de Fomento Ángel Ossorio y Gallardo [1873-1936].

El ingreso de España en la OIT de mano de Eduardo Dato y su presencia en la Conferencia de Washington, impelía a las autoridades del Estado liberal a insistir en la reforma social estatal y centralizada. Este fue el fin del Ministerio de trabajo (1920) debería regular positivamente materias referentes al contrato colectivo de trabajo, la obligatoriedad de los seguros sociales, la personalidad jurídica sindical, la jornada laboral regulada, etc. Pero el problema surgió pronto; en las primeras discusiones sobre la reforma de la vigente Ley de Asociaciones de 1887, y se evidenciaban diferentes posturas sobre el modo de afiliación sindical (voluntaria u obligatoria). Este debate evidenciaba los límites del liberalismo oficial en materia político-social, y las futuras posiciones sobre el papel político de las organizaciones profesionales.

A estos proyectos reformistas-sociales de organización corporativa antes mencionados, se unía un fenómeno no siempre advertido: la autodefensa corporativa de trabajador y de la profesión. Junto a las primeras formas de asociación obrera mutualista y sindicalista, el mundo de las clases medias urbanas y profesionales liberales comenzó su propia reconstrucción post-gremial. La profesión se fue 
convirtiendo no sólo en una realidad jurídica, sino incluso en un posible modelo de reorganización política y social, arquetipo de valores morales, religiosos y armonizadores. La colegiación obligatoria y la conciencia grupal se fueron convirtiendo en rasgos distintivos de nuevas asociaciones profesionales, concebidas por distintos doctrinarios en alternativa a los políticos profesionales de formación jurídica (Villacorta Baños 1989: 5-6).

A la patronal encabezada por Fomento del trabajo nacional, o a la movilización regeneracionista de la Asamblea de Cámaras de Comercio de Zaragoza (1899), y el breve partido Unión nacional (1890) de Benito Paraíso [1849-1930], se unieron las pretensiones corporativas de los Colegios profesionales. Los Colegios de médicos, de notarios, de abogados, de maestros o de funcionarios se fueron sumando a las corporaciones patronal, militar y eclesiástica como factor de poder, apoyo y legitimación en el ejercicio político de la Restauración, pero también en el debate sobre la ejecución de las medidas regeneracionistas. Las nacientes clases medias urbanas tomaban ejemplo de la movilización corporativa patronal, buscando influir en las grandes decisiones ejecutivas, orientando la política económica, social e incluso internacional, sin recurrir a la vida política partidocrática. Industriales y empresarios agrarios luchaban en pro o en contra del Arancel proteccionista, de la Política social reformista, de tribunales de arbitraje, de intervención policial en huelgas industriales y revueltas campesinas.

"Un signo de naturaleza social y política" común a grupos profesionales de naturaleza distinta -apuntaba Villacorta- se desprendía de la "historia corporativa" en 1922: la "nacionalización o socialización" de las funciones profesionales. La experiencia juntista y asambleísta entre 1914 y 1918, no solo militar y parlamentaria, marcó este camino: la aspiración médica (Unión médica nacional, 1914), el reformismo notarial y jurídico (la Unión judicial, 1921), la movilización de funcionarios de Hacienda, de Magisterio primario (Unión nacional de Maestros, 1915), de Universidades, de funcionarios administrativos, de Correos y telégrafos (huelga de telégrafos de abril de 1919 y de Correos de agosto de 1922). A ellos se unían las movilizaciones de estirpe regeneracionista de Organizaciones y Patronales agrarias, que como en el caso de Valencia, "planteaban la necesidad de la representación directa de los intereses económicos" durante la época de consolidación del régimen canovista. Sectores obreros y burgueses coincidían, en estos años, en la representación político-social del mundo del trabajo (Vicente Castillo, 2002: 85).

El "creciente protagonismo de los factores colectivos de la vida social" -señala Villacorta- llevaba no solo a "la redefinición, desde ese espacio colectivo, de las funciones desempeñadas por los distintos grupos sociales", sino también "del Estado como cifra y compendio sociológico de esos mismos grupos sacudidos por la situación de crisis que les impelía a buscar en las filas de recluta de un organismo burocrático el último refugio para el mantenimiento de la su identidad social" (Villacorta Baños, 1989, 487). 
B) La Organización nacional corporativa de M. Primo de Rivera [1923-1930].

Ante la crisis económica y la huelga revolucionaria, presente en la etapa conocida como "trienio bolchevique" [1918-1922], bajo la Dictadura de M. Primo de Rivera se instauró en 1926 un sistema nacional conocido como Organización Corporativa Nacional (Gómez Navarro, 1991: 45-48). Este sistema, basado en la sindicación libre pero bajo la Corporación obligatoria, se extendió por toda España, reuniendo en su seno a representantes patronales y obreros, bajo el objetivo de acabar con la "lucha de clases", y de la mano de una amplia Política social impulsada por el Ministro de Trabajo Eduardo Aunós. En esta elaboración colaborarán, decisivamente, la Unión General de Trabajadores (UGT) y figuras emblemáticas del socialismo como Francisco Largo Caballero [1869-1946], quien ocupará el cargo de Consejero de Estado; también lo harán, en la gestión administrativa, miembros destacados del recién disuelto IRS como P. Zancada, J. Gascón y Marín [1875-1962], R. Oyuelos [1865-1943], A. Gallart y Folch [1893-1972], pese al público alejamiento del máximo teórico del liberalismo organicista, el constitucionalista Adolfo G. Posada [18601944]. A esta labor también se consagraron, entre otros, el ingeniero y militar José Marvá y Mayer [1846-1942], krausistas como Leopoldo Palacios Morini [1876-1952], reformistas católico-sociales como Pedro Sangro Ros de Olano, marqués de Guad-elJelú [1878-1959], o Álvaro López Núñez (1865-1936).

Este sistema corporativo se desplegó en tres fases: la primera partiría de la intervención mediadora del Estado en la creación de los organismos paritarios y el fomento de la corporativización interclasista; tras ella, una segunda fase sancionaría como "norma jurídica" ciertos fallos obligatorios de dichos organismos; y la tercera fase concluiría con una ONC como sistema estatal que convertiría al organismo corporativo institución "permanente de arbitraje y en una jurisdicción regular y obligatoria" (Aunós, 1927). De esta manera, el RDL de 12 de mayo de 1926 configuraba el régimen legal constitutivo de las corporaciones agrarias en España, y el RDL de 26 de noviembre de ese mismo año aprobaba la Organización Corporativa Nacional (Montoya Melgar, 1980: 36-38).

El Real Decreto-Ley de organización corporativa nacional (1926) generalizaba a nivel nacional los primeros Comités paritarios ensayados, desde 1924, en varias áreas geográficas. Este texto legislativo convertía así al Comité paritario en el mecanismo estatal y general de arbitraje y conciliación laboral; en él participarían en igualdad de condiciones patronos y obreros bajo supervisión pública, estableciendo una la corporación obligatoria, aunque con sindicación libre. De esta manera se dibujaba un organismo de conciliación obligatorio y permanente, de base local, que se integraba en una red de coordinación y de supervisión de base nacional; integración que edificaba un sistema burocrático bajo el control y dirección estatal a través de un conjunto de representantes gubernamentales (Aunós, 1928:22).

El preámbulo de este Real Decreto definía a la ONC como una gran estructura jerárquica, armónica e interclasista de regulación de las asociaciones y relaciones profesionales en el ámbito comercial e industrial. "Los elementos que integran la vida profesional española se organizarán sobre la base de Cuerpos especializados y clasificados, a cada uno de los cuales se dotará de representación oficial, mediante la 
designación de Comités paritarios de jurisdicción graduada" introducía el artículo primero del citado Real decreto. Cada asociación, oficio o grupo de un área profesional sectorial se integraba en corporaciones obligatorias (tanto patronos como obreros), constituyendo los Comités Paritarios los representantes de cada grupo integrado en la Corporación "natural". El sistema se estructuraba jerárquicamente en cinco niveles: Comité paritario, Comisiones mixtas de Trabajo, Comisiones mixtas provinciales, Consejos de corporaciones y Comisiones delegadas de trabajo, y ordenada sobre una clasificación de 27 corporaciones profesionales agrupadas en tres grandes grupos: producción primaria, secundaria y de Servicios, comercio y varios. Sistema posteriormente completado con un Reglamento-tipo de Comités paritarios (Real orden de 8 de noviembre de 1927), el texto refundido del decreto ley (introduciendo las modificaciones de 1927 y 1928), la organización corporativa de la agricultura, la vivienda y del trabajo a domicilio (Real decreto-ley de 12 de mayo de 1928).

La base de todo el sistema era el Comité de Paritario. Este organismo, que se situaba como una entidad de derecho público, adquiría funciones y atribuciones bajo delegación y descentralización estatal, siendo integrado por representantes patronales y sindicales en igual número, pero presidido por presidentes y vicepresidentes de elección ministerial. De esta manera, fue diseñado como órgano obligatorio con representantes de patronos y obreros de una determinada industria (elegidos libremente dentro de asociaciones igualmente de libre elección), que se agrupaban y clasificaban sintéticamente según oficio, dando lugar a la Corporación profesional. Los representantes profesionales eran elegidos a través de sus asociaciones de origen o pertenencia, las cuales presentaban las candidaturas y componía el censo sociolaboral.

\section{C) Los Jurados mixtos republicanos [1931-1936].}

Tras eliminar el sistema corporativo anterior, la Segunda República impulsó un sistema diferente en la gestión de las relaciones laborales entre los actores de la producción: los Jurados mixtos (Martínez, 2009: 522-524). De la mano del nuevo Ministro de Trabajo, el socialista Largo Caballero, que había colaborado activamente en el modelo primorriverista, los primeros Jurados Mixtos fueron creados por Decreto de 7 de mayo de 1931 para arbitrar las condiciones de contratación y vigilar el cumplimiento de la normativa laboral en el sector agrario. La primera función de estos Jurados Mixtos de Trabajo Rural, Propiedad Rústica e Industrias Agrícolas fue determinar los salarios de la campaña agrícola de ese año. Con apoyo gubernamental, los representantes sindicales lograron subidas substanciales en los jornales, que de 3,50 pesetas pasaron a oscilar entre las 5 y las 10 pesetas diarias. El Decreto establecía tres tipos: a) Jurados Mixtos de trabajo rural, integrados por representantes de propietarios y de trabajadores sindicados para reglamentar las condiciones laborales; b) Jurados Mixtos de propiedad rústica, que regulaban las relaciones entre los propietarios de tierras y los arrendatarios; c) Jurados mixtos de la producción y de las industrias agrarias (Cabrera Calvo-Sotelo, 1987: 67-69). 
La Ley, aprobada por las Cortes el 27 de noviembre de 1931, amplió los Jurados Mixtos a la industria, los servicios y la actividad profesional, y los clasificó por ramos. Había Jurados locales o comarcales, provinciales y nacionales. Sus vocales eran elegidos paritariamente por las asociaciones patronales y obreras inscritas en el censo del Ministerio de Trabajo y los presidía un representante del Ministerio (con esta Ley, los Jurados Mixtos agrarios se integraron en el sistema general, como órganos de mediación laboral y de negociación de los convenios colectivos). Su misión era mediar en los conflictos laborales -aumentos salariales, condiciones de trabajo, etc.estableciendo un dictamen conciliatorio en cada caso. Si el dictamen era rechazado por alguna de las partes, el Jurado lo podía remitir al Ministerio, que podía a su vez elevarlo, en última instancia mediadora, al Consejo Superior de Trabajo.

\section{D) De la Magistratura de Trabajo a los Convenios Colectivos [1939-1977].}

Entre 1939 y 1977, el régimen franquista estableció un sistema de corporativismo de Estado como instrumento de control político de la estructura de las relaciones laborales; todo ello dentro de una concepción de la Política Social sometida al pluralismo social limitado y a la armonización jerárquica del sistema productivo (Ysas y Molinero, 1992: 33-34). Entre ambas fechas, el mismo evolucionó de una Magistratura de Trabajo que impuso la conciliación obligatoria entre productores (obreros y patronos) de manera individual, hacia un sistema de Convenios Colectivos desde 1958 que reconocía las facultades de categorías profesionales, áreas de trabajo o sectores productivos a dirimir como entidades grupales sus conflictos de manera pactada,

En nuevo sistema de relaciones laborales de posguerra, delimitado por el Fuero del Trabajo (1938) y controlado por la Organización sindical española (1940), generaron una Administración social corporativa y jerárquica, definida por el jurista Eugenio Pérez Botija [1911-1966] como un proceso de institucionalización del corporativismo de Estado, dentro de una visión de la Política social fundada en "puras directrices económicas, métodos de sociología aplicada, preocupaciones ético-religiosas y de política económica para alumbrar soluciones de lege ferenda" (Pérez Botija, 1952: $15)$.

La Magistratura de Trabajo, aprobada por el D. de 13 de mayo de 1938, sancionó la intervención superior y neutral del Estado en cuestiones sociolaborales, manteniendo "la intervención de representantes del interés de categoría en el proceso individual en materia de trabajo" (aunque, a veces, este proceso individual ventilaba cuestiones de interés específico colectivo), negando la participación de los "elementos profesionales de los representantes de la lucha de clases. Frente a los anteriores Jurados mixtos republicanos, acusados de fomentar la lucha de clases, esta Magistratura establecía la conciliación obligatoria, estableciendo una norma inconmovible e imperativa ajena a toda fórmula de arbitraje voluntario, sobre las relaciones jurídico-laborales entre obreros y patronos.

Esta institución rompía con la tradición jurídica de que en los organismos laborales intervengan patronos y obreros en paridad de número y facultades. La legislación procesal-laboral española no reconocía la posibilidad de los conflictos 
colectivos, sólo conflictos individuales de trabajo, al no existir más que un sindicato oficial, el "sindicato vertical". No podían existir "litigios colectivos", y apenas "conflictos intersindicales" entre sindicatos de una misma rama profesional (organización sindical corporativa e institucional). De esta manera, las categorías sindicales no podían entrar en conflicto entre sí, al no existir categoría antagónicas, sino solo intereses integrados; por ello en España "en lugar de una Administración corporativa o sindical, debería concebirse más bien nuestros sindicatos como órganos especiales de la Administración".

Posteriormente llegó el turno de los Convenios Colectivos. La promulgación de la Ley de Convenios Colectivos en 1958 abría de nuevo, aunque de manera limitada y controlada, la vía a las negociaciones y convenios colectivos, retomada definitivamente por el II Plan de Desarrollo (1969), que permitió posteriormente la aprobación de la Ley de 19 de Diciembre de 1973 sobre Convenios Colectivos. Con esta Ley se limitaba la capacidad fiscalizadora a las Ordenanzas y Reglamentaciones estatales a la hora de fijar "las bases mínimas" de los Convenios, y aunque se mantenía el arbitraje obligatorio, se permitía un plazo bianual de negociación, se agilizaba el procedimiento de tramitación, y se ampliaba el margen de actuación de la Organización Sindical española. Esta Ley especificaba que la negociación colectiva podía tener lugar, bien en el Jurado de la Empresa en cuestión, bien entre patronos y obreros, en los locales sindicales a nivel local, provincial o nacional. También preveía una posibilidad de "arbitraje obligatorio" en el caso de que las partes no pudieran llegar a un acuerdo. Este fue el caldo de cultivo para el nacimiento y desarrollo del sindicalismo paralelo al oficial, y centrado en las Comisiones Obreras (CCOO).

\section{E) Los Pactos sociales de la Transición [1978-1984].}

Víctor Pérez advirtió, a finales de los años ochenta, sobre la persistencia de ciertas formas corporativas de representación política en España, tras el ocaso del organicismo social y el desmantelamiento de la práctica totalidad de la economía corporativa nacional. Inicialmente las denominó como "neocorporativas", pero posteriormente amplió su definición hacía el "mesogobierno" (Pérez, 1987, 95-96). Resultaban ser "políticas de pactos sociales y de intermediación de intereses entre organizaciones sindicales y patronales" con implicaciones políticas. Su naturaleza extraparlamentaria, y supuestamente extra-ideológica, conducía a mecanismos técnicos que no respondían exactamente al modelo tecnocrático popularizado por William H. Smyth o al sistema de gestión técnica planteado por James Burnham [1905-1987] en su "revolución de los directores". En el caso español, para Martínez Alier y Roca Jusmet suponía la "reconstrucción del orden burgués" tras el franquismo, mediante una "primacía de la economía" sobre la política y una serie prácticas neocorporativistas que favorecía, en este contexto, un aumento de la desigualdad en la distribución del ingreso entre salarios y rentas de la propiedad, y la desactivación de la presión sindical (Martínez y Roca, 1988).

"Una buena parte de las actividades estatales tienen una significación económica señalaba M. García Pelayo- y una buena parte de las actividades económicas tienen una significación política". Así el neocorporativismo borraba las distinciones entre 
decisión política y gestión económica, entre actores políticos y actores económicos en muchos sectores públicos; un hecho que alarmaba a parte de la sociedad política por suponer la "intromisión del poder privado en la esfera pública", o por "desvirtuar la acción soberana del legislativo" (García Pelayo, 1991a: 1665-1666). Pero Wilhelm Röpke [1899-1966] reducía toda expresión corporativa a una manifestación económica colectivista más, otra cara del Estado social intervencionista, "ya que ni la idea romántica de auto-administración económica (Estado de gremios, corporativismo) ni el desarrollo en magna escala de las cooperativas constituyen una alternativa viable ni nos ofrecen un nuevo orden económico que no deba regularse sea por los precios, sea por las órdenes de las autoridades" (Röpke, 1947: 26).

Pero durante la década de los setenta comenzó a analizarse "el papel de los Sindicatos en la nueva sociedad", que H.J. Laski había anunciado a mediados de siglo (Laski, 1951: 22). Se hablaba ahora del "neocorporativismo" como paradigma explicativo de la integración política de los nuevos fenómenos de autoorganización social, desde los "grupos de presión" y sindicatos al llamado "Tercer Sector" (Solé, 1984), pasando por las modalidades del movimiento asociativo comunitario. Nacía un nuevo Estado pluralista o "Estado social corporativo" para Charles F. Sabel, que Alan Cawson definía como "corporativismo liberal y democrático" (Sanz Menéndez, 1994: $1-3)$.

Dentro de este fenómeno popularizado por P.C. Schmitter como neocorporativismo (Schmitter, 1978: 135-138), en 1978 comenzó en España una nueva "política de concertación" a nivel sociolaboral denominada como "neocorporativa", ante la crisis económica de estos años. Los primeros "Pactos de la Moncloa", y el Acuerdo económico y social (AES), de 9 de Octubre de 1984, abrieron el periodo de Pactos sociales entre organizaciones sindicales y organización patronales (Pérez Yruela, 1996).

El primero de los grandes pactos sociales que emanaron de esta estrategia política fueron los Pactos de la Moncloa, firmados en octubre de 1977 por los principales partidos políticos (las organizaciones sindicales y patronales no lo firmaron al estar en proceso de reestructuración, aunque en general fueron favorables). El punto de arranque fue el Acuerdo Básico entre la CEOE y UGT de julio de 1979, que culminó en el Acuerdo Marco Interconfederal (AMI) de enero e 1980, y el consenso entre UCD y PSOE sobre el Estatuto de los Trabajadores, aprobado en marzo de 1980. El Acuerdo Nacional de Empleo (ANE) de julio de 1981, firmado entre el gobierno, CEOE, CCOO y UGT sustituyó al AMI. El último gran pacto de esta época, y que culminó la política de concertación social fue la firma por el gobierno, UGT y CEOE del Acuerdo Económico y social (AES), con una vigencia de 2 años.

Este modelo "neo-corporativo" colaboró en la definición de algunos elementos claves de la política económica y social, permitió el equilibrio de sistema político, y reforzó el papel de estas organizaciones socio-profesionales (Roca Jusmet, 1993). Los sindicatos y la patronal adquirieron una jerarquía "oficial" dentro de de la Administración pública, y un protagonismo esencial en la configuración de las políticas macroeconómicas en los pactos sociales desarrollados entre 1977 y 1984 . La relativa cooperación entre UGT y CEOE, y en menor medida con CCOO, permitió 
desarrollar la incorporación de la voz y el voto de las organizaciones socioprofesionales en las decisiones de política económica y salarial (Morán, 1996: 14-15).

El punto culminante de este proceso fue la creación del Consejo Económico y Social (CES) en 1991 (por la Ley 21/1991, de 17 de junio), que se concretó en un "órgano consultivo del gobierno de la nación en materia socioeconómica y laboral". Este organismo se derivaba simbólicamente de los arts. 91 y 131 de la Constitución española (CE), pero se materializa a través de la potestad ejecutiva y de la legislación ordinaria. El CES español poseía una entidad político-social propia, en dos ramas interrelacionadas: la política legislativa laboral y la política económica. En ambas ramas se mostraba como manifestación de las nuevas tendencias corporativas, dentro de las estructuras del Estado del Bienestar; pero su encaje constitucional lo configuraba como medio adicional de estímulo de la participación ciudadana y de representación institucional de intereses fuera de los tradicionales instrumentos de mediación política. También cabe señalar que el Código civil solo reconoce, en sentido genérico, a la Corporación en el ámbito de las asociaciones, como "personas jurídicas privadas" cuya capacidad civil se "regulara por las leyes que las hayan creado o reconocido" (Título II, capítulo II, arts. 35-39).

A la creación final del CES se llegó a través de un largo proceso:

- En los últimos coletazos del régimen franquista, durante el Proyecto de Ley de Reforma de la Leyes fundamentales (1976), el Gobierno de Arias Navarro, intentó impulsar un organismo de colaboración socioeconómica, frenado a última hora en las Cortes.

- Durante el cambio político el Gobierno Suárez desarrolló un Anteproyecto de CES (21 de octubre de 1976) como órgano tripartito de representación y negociación, que fue rechazado por los Sindicatos.

- El Proyecto de Reestructuración del antiguo Consejo de Economía nacional (CEN), que aun se mantenía nominalmente, diseñó un nuevo "organismo consultivo asesor y técnico en los asuntos de importancia que afectaran a la economía nacional" (4 de noviembre de 1976).

- Proyectos postconstitucionales: propuestas contenidas en el ABI (1979) y en el AES (1984), propuestas del PSOE (1979), UGT (1984), CCOO (1988) y de USO (1988), y Borradores de Ley de Ramón Tamames (1981) y de Anteproyecto de Ley del Ministerio de Trabajo (1986).

\section{Conclusiones}

El Corporativismo, término polisémico donde los halla en la ciencias sociales y jurídicas, no es un problema histórico, sino una realidad no siempre advertida como modalidad de la Política social (Giner, 1979). En ella el Trabajo, organizado siempre de manera grupal y jerárquica, adquiere rango de instrumento al servicio de la Política para sus fines de ordenación social y control económico. Las recurrentes crisis del modelo de Economía de Mercado, en especial en su impacto en el sistema político 
democrático, vuelve a poner de manifiesto el papel de las corporaciones, bien extraparlamentarias bien reconocidas por el poder jurídico-político, en el funcionamiento de las instituciones del Estado y del Mercado, en la mediación entre la política y la economía; pero determinan, especialmente, el verdadero horizonte las organizaciones sociolaborales en el funcionamiento de las directrices político-sociales, $\mathrm{y}$ en especial del sistema de relaciones laborales presente y futuro.

\section{Bibliografía}

Aunós, E. (1928). Las corporaciones de trabajo en el Estado moderno. Madrid: Biblioteca Marvá.

Barrio Alonso, A. (1996). El sueño de la democracia industrial. Sindicalismo y democracia en España. 1917-1923. Santander: Servicio de publicaciones de la Universidad de Cantabria.

Cabrera Calvo-Sotelo, M. (1987). Las organizaciones patronales ante la conflictividad social y los Jurados Mixtos. En VVAA, La II República una esperanza frustrada: actas del Congreso Valencia Capital de la República (pp. 65-82). Valencia.

De Alos-Moner, R. (2008). Segmentación de los mercados de trabajo y relaciones laborales. El sindicalismo ante la acción colectiva. Cuadernos de Relaciones laborales. Vol. 21 Núm. 1, 123-148,

De la Calle, Ma . D. (1989). La Comisión de Reformas Sociales 1883-1903. Política social y conflicto de intereses en la España de la Restauración. Madrid: Ministerio de Trabajo.

De Laubier, P. (1984). La Polítique sociale dans les societés industrielles. 1800 à nos tours. París: Economica,

Del Rey Reguillo, F. (1992). Propietarios y patronos. La política de las organizaciones económicas en la España de la Restauración. Madrid: Ministerio de Trabajo.

Durkheim, E. (1982). La división del trabajo social, Madrid: Akal.

Edwards, PKK. (1992). El conflicto laboral: temas y debates en la investigación reciente. Cuadernos de Relaciones laborales. Núm. 3, 139-192.

Estudios Económicos y Sociales (1922). Anteproyecto de Ley sobre Contrato de Trabajo. Madrid: Sucesores de Rivadeneyra.

Fernández Riquelme, S. (2008). Mijail Manoilescu y el Paradigma del corporativismo en el siglo XX. La Razón histórica: revista española de historia de las ideas políticas y sociales, Núm 4, 18-22

Fortshoff, E. (1967). Sociedad industrial y Administración pública. Madrid: INAP. 
Freund, J. (1998). La Cuestión social. Cuadernos de Trabajo Social. Núm. 11, 278-282.

García Canales, M. (1977). La teoría de la representación en la España del siglo XX. Murcia: Publicaciones del Departamento de Derecho público de la Universidad de Murcia.

García Delgado, J.L. (2002). La modernización económica en la España de Alfonso XIII. Madrid: Espasa.

García Pelayo, M. (1991). Las Transformaciones del Estado Contemporáneo, Madrid: Alianza Editorial.

Giner, S. (1979). La Sociedad corporativa. Madrid: CIS.

Gómez Navarro, J.L. (1991). El Régimen de Primo de Rivera. Reyes, dictaduras y dictadores. Madrid: Cátedra.

Incisa, L. (1982). Corporativismo. En N. Bobbio y N. Matteucci, (Coor), Diccionario de política, vol. I, (pp. 431-437). Madrid: Siglo XXI ed.,

Instituto de Reformas Sociales (1919). El problema obrero en Gran Bretaña. La Conferencia Industrial y los informes del Comité Whitley. Madrid: Sobrinos de la Sucesora de Minuesa.

Laski, H.J. (1951). Los Sindicatos en la nueva sociedad. México: Fondo de Cultura Económica.

Linz, J.J. (1988). Política e intereses a lo largo de un siglo en España, 1880-1980. En S. Giner y M. Pérez Yruela, (eds.), El corporatismo en España (pp. 67- 123). Barcelona: Ariel.

Martínez Alier, J. y Roca Jusmet, J. (1993). Economía política del corporativismo en el Estado español: del franquismo al posfranquismo. Reis, Núm. 41, 25-62.

Martínez Gómez, P. (2009) "De los comités paritarios de la dictadura a los Jurados Mixtos de la República: ¿continuidad o reforma?. En J.L. Casas y F. Durán Alcalá, (Coord.), 1931-1936, De la República democrática a la sublevación militar: Actas del IV Congreso sobre Republicanismo (pp. 515-536). Madrid.

Molina, J. (2004). La política social en la Historia. Murcia: Isabor.

Monereo, J.L. (2003). La Reforma social en España. Adolfo Posada. Madrid: Ministerio de Trabajo y Asuntos Sociales.

Montero Aroca, J. (1976). Los Tribunales de Trabajo, 1808-1936. Jurisdicciones especiales y movimiento obrero. Valencia: Servicio de publicaciones de la Universidad de Valencia.

Montoya Melgar, A. (1980). Ideología y lenguaje en las leyes laborales de España: la dictadura de Primo de Rivera. Murcia: Secretariado de publicaciones de la Universidad de Murcia. 
Morán, A. (1996). Auge y crisis de los grandes acuerdos sociales de los 80 . Cuadernos de Relaciones laborales. Núm. 9, 13-55.

Pérez, V. (1987). El retorno de la sociedad civil. Madrid: Instituto de Estudios económicos.

Pérez Yruela, M. (1996). Corporatismo y Estado del Bienestar. En S. Giner y S. Sarasa, (Eds.), Buen gobierno y política social (pp. 133-150). Barcelona: Ariel.

Roca Jusmet, J. (1993). Pactos sociales y política de rentas: el debate internacional y la experiencia española (1977-1988). Madrid: Ministerio de Trabajo y Seguridad Social.

Röpke, W. (1947). La crisis social de nuestro tiempo. Madrid: Revista de Occidente.

Sanz Menéndez, L. (1994). El corporatismo en las sociedades industriales avanzadas: veinte años de debates sobre intermediación de intereses y políticas públicas. Madrid: CSIC.

Schmitter, P. C. (1978). Reflections on Mihail Manoilesco and the Politicals Consequences of Delayed-dependent Development on the Periphery of western Europe. En K. Jowie, (Ed), Social Change in Romania, 1860-1940 (pp. 135-138). Berkeley: Institute of International Studies,

Solé, C. (1984). El debate corporativismo-neocorporativismo. Reis, Núm. 26, 9-28.

Valera, J. (2001). Los amigos políticos. Partidos, elecciones y caciquismo en la Restauración (1875-1900). Madrid: Marcial Pons.

Vicente Castillo, J. (2002). La política de los camaleones: los conservadores valencianos durante la Restauración. Valencia: PUV.

Zancada, P. (1929). Derecho corporativo español. Madrid: Bosch.

Pérez Botija, E. (1952). Curso de Derecho del trabajo. Madrid: Dosset.

Sánchez Reinón, M. (1996). El conflicto y problemático proceso histórico de institucionalización de la negociación colectiva en España (1873-1936). Cuadernos de Relaciones laborales. Núm. 9, 209-225.

Villacorta Baños, F. (1989). Profesionales y Burócratas: Estado y poder corporativo en la España del siglo XX. Madrid: Siglo XXI.

Ysas, P., y Molinero, C. (1992). Productores disciplinados: control y represión laboral durante el franquismo (1939-1958). Cuadernos de Relaciones laborales. Núm.3, 33-50. 